J Neural Transm (1991) [Suppl] 34: 2013-210

(C) by Springer-Verlag 1991

\title{
Glutamate receptor antagonism: neurotoxicity, anti-akinetic effects, and psychosis
}

\author{
P. Riederer' ${ }^{\prime}$ K. W. Lange', J. Kornhuber' ${ }^{\prime}$, and K. Jellinger ${ }^{2}$ \\ 'Clinical Neurochemistry, Department of Psychiatry, University of Würzburg, \\ Federal Republic of Germany \\ ${ }^{2}$ Ludwig Boltzmann Institute of Clinical Neurobiology, Lainz Hospital, \\ Vienna, Austria
}

\begin{abstract}
Summary. There is evidence to suggest that glutamate and other excitatory amino acids play an important role in the regulation of neuronal excitation. Glutamate receptor stimulation leads to a non-physiological increase of intracellular free $\mathrm{Ca}^{2+}$. Disturbed $\mathrm{Ca}^{2+}$ homeostasis and subsequent radical formation may be decisive factors in the pathogenesis of neurodegenerative diseases.

Decreased glutamatergic activity appears to contribute to paranoid hallucinatory psychosis in schizophrenia and pharmacotoxic psychosis in Parkinson's disease. It has been suggested that a loss of glutamatergic function causes dopaminergic over-activity. Imbalances of glutamatergic and dopaminergic systems in different brain regions may result in anti-akinetic effects or the occurrence of psychosis. The simplified hypothesis of a glutamatergicdopaminergic (im)-balance may lead to a better understanding of motor behaviour and psychosis.
\end{abstract}

\section{Introduction}

It is only recently that excitatory amino acid receptors have been discovered. Through the use of selective agonists and antagonists it has become evident that these receptors consist of different subtypes (for review see Watkins et al., 1990). At present the most useful classification provides the following excitatory amino acid receptor subtypes: N-methyl-D-aspartate (NMDA) receptors, kainate receptors, quisqualate receptors or $\alpha$-amino-3hydroxy-5-methyl-4-isoxazolepropionate (AMPA) receptors, metabotropic receptors and L-aminophosphonobutyrate (L-AP4) receptors. Some important features of these excitatory amino acid receptor subtypes are given in Table 1. It is evident that these receptors fulfill a variety of different physiological functions depending on their regional and subregional location, their pre- or postsynaptic localization, the neurotransmitter system at which they are located and their quantitative distribution. 
Table 1. Glutamate receptor subtypes: major pharmacological profile and localization

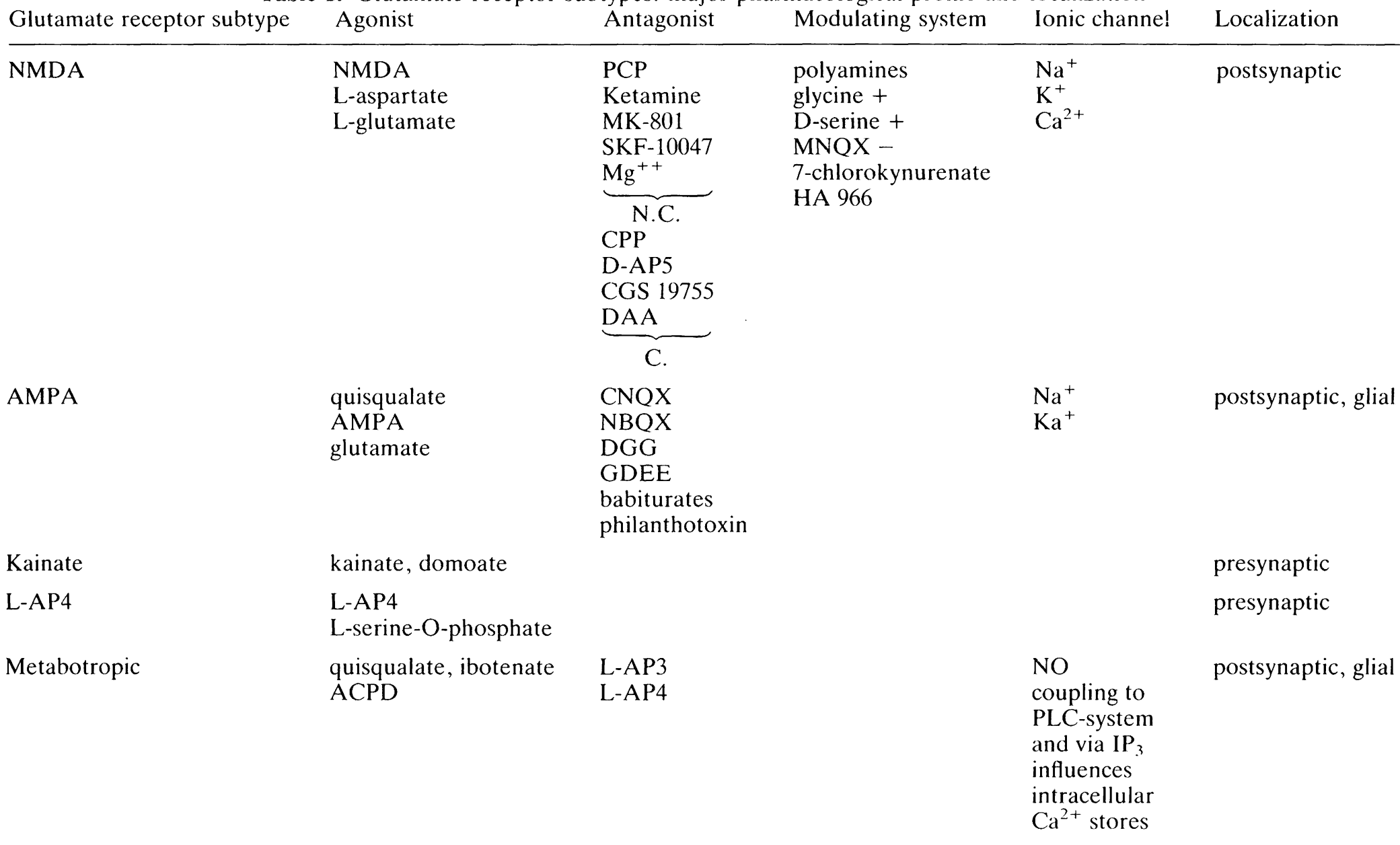

Abbreviations: $C$. competitive; N.C. non-competitive; $A C P D$ 1-amino-cyclopentane-1, 3-dicarboxylic acid; $A M P A \alpha$-amino-3-hydroxy-5methyl-4-isoxazolepropionic acid; $D$-AP5 D-2-amino-5-phosphonopentanoic acid; $L$-AP3 L-amino-3-phosphonopropionic acid; $L$ - $A P 4$ L-2-amino-4-phosphonobutanoic acid; CGS 19755 4-phosphonomethyl-2-piperidinecarboxylic acid; $C N Q X$ 6-cyano-7-nitroquinoxaline-2, 3-dione; $C P P( \pm)$-2-carboxypiperazine-4-yl-propyl-1-phosphonic acid; $D A A$ D-aminoadipate; $D G G$ D-glutamylglycine; $G D E E$ glutamic acid diethyl ester; HA 966 1-hydroxy-3-amino-pyrrolidin-2-one; MK80I (+)-5-methyl-10, 11-dihydro-5H-dibenzo[a,d]cyclohepten-5,10imine maleate; $M N Q X$ 6,8-dinitroquinoxalinedione; $N B Q X$ 6-nitro-7-sulphamobenzo[f]quinoxaline-2,3-dione; NMDA N-methyl-Daspartate; $N O$ nitric oxide; $P C P$ phencyclidine; $S K F-10047 \mathrm{~N}$-allyl-normetazocine; + activating; - inhibiting 
NMDA receptors are involved in the regulation of intracellular free $\mathrm{Ca}^{2+}$-concentrations. It has therefore been suggested that glutamate and other excitatory amino acids play an important role in the regulation of neuronal excitation and may bring about neuronal destruction if administered in sufficient excess.

\section{Glutamate toxicity and neurodegeneration}

The regulation of $\mathrm{Ca}^{2+}$ and its compartmentalization is important for both presynaptic and postsynaptic events. Alterations in the extracellular/ intracellular $\mathrm{Ca}^{2+}$ ratio can produce deleterious changes in cell function.

Altered $\mathrm{Ca}^{2+}$ homeostasis may influence a variety of physiological cell functions including $\mathrm{Ca}^{2+}$ transport systems, $\mathrm{Ca}^{2+}$ binding proteins and $\mathrm{Ca}^{2+}$-activated proteases (Gibson and Peterson, 1987). A non-physiological increase of intracellular free $\mathrm{Ca}^{2+}$ leads therefore to a dysregulation of membrane-dependent processes. This is generally accompanied by a loss of energy supply to the cell, and the loss of ATP in particular alters the biochemical homeostasis of the cell.

Neurodegeneration is caused or accompanied by $\mathrm{Ca}^{2+}$ influx and intracellular $\mathrm{Ca}^{2+}$ mobilization. It has been suggested that excitatory amino acids play an important role in excitatory neurotoxicity and neurodegeneration (for review see Meldrum and Garthwaite, 1990). Glutamate with its high concentration in the mammalian brain is the probable neurotransmitter at most excitatory synapses and the most likely excitatory amino acid toxin. NMDA receptor channels permit a large $\mathrm{Ca}^{2+}$ influx and there is evidence to suggest that toxic $\mathrm{Ca}^{2+}$ entry occurs mainly through these channels (Garthwaite and Garthwaite, 1987). The activation of proteases and other $\mathrm{Ca}^{2+}$-dependent enzymes such as protein kinase $\mathrm{C}$, phospholipases and $\mathrm{Ca}^{2+}$-calmodulin-dependent protein kinase II may contribute to glutamate toxicity (Meldrum and Garthwaite, 1990). The substantial increase of $\mathrm{Ca}^{2+}$. activated proteases such as calpains causes destruction of microtubules, neurofilaments, etc. and may induce derangement of structural membrane integrity. Calpains also convert xanthine dehydrogenase to xanthine oxidase and free radicals are subsequently generated during purine metabolism. Increased phospholipase activity results in the release of lipids and leads to production of arachidonic acid, which can be metabolized to produce free radicals. Radicals increase lipid peroxidation of membrane constituents and enhance the release of excitatory amino acids. In addition, arachidonic acid blocks the uptake of glutamate into glial and neuronal cells.

All of these pathological events cause a catabolic state in which nutritional supply decreases. Neuronal processes are eventually destroyed and neurodegeneration becomes uncontrolled and progressive. In Parkinson's disease and in Alzheimer's dementia a loss of about $70 \%$ of cell bodies in the substantia nigra pars compacta and the nucleus basalis Meynert, respectively, is necessary before the major clinical symptoms are observed. Whether or not disturbed $\mathrm{Ca}^{2+}$ homeostasis and radical formation are 
decisive pathobiochemical factors in these disorders is the subject of intensive research.

There is experimental evidence to suggest that excitotoxic mechanisms contribute to neuronal loss occurring as the result of cerebral ischaemia (for review see Meldrum and Garthwaite, 1990). Current knowledge suggests that a loss of glutamatergic function is a plausible hypothesis for the occurrence of productive symptoms in schizophrenia (see below). Decreased glutamatergic function may in theory be accompanied by a reduced rate of cerebral infarction in patients with schizophrenia. In order to examine this proposition we took an unselected series of 880 patients with neurological or psychiatric diseases who died at Lainz Geriatric Hospital, Vienna, between 1981 and 1988. In addition to routine autopsy, examinations were performed by a neuropathologist (K. J.). The number and percentage of patients dying of cerebral infarction was determined for the various diagnoses (Table 2). The number of such deaths was highest in the group of patients with a history of cerebral infarction. In contrast to neurological diseases, psychiatric disorders showed the lowest death rate caused by cerebral infarction. This preliminary evaluation is in line with the theories of decreased glutamatergic activity in schizophrenia and enhanced excitatory amino acid release in patients with cerebral infarction. It is interesting to note that cerebral infarction was not found in a group of 40 depressed patients. It is not known whether this can be directly related to decreased glutamatergic activity or to antidepressant therapy which may antagonize NMDA receptor function (Reynolds and Miller, 1988).

Table 2. Neurological and psychiatric patients dying of neuropathologically confirmed cercbral infarction $(1981-1988)$

\begin{tabular}{|c|c|c|c|c|c|c|c|}
\hline Disease & $\begin{array}{l}\text { Patients } \\
\quad(\mathrm{n})\end{array}$ & $\begin{array}{l}\text { Sex } \\
\text { F/M }\end{array}$ & $\begin{array}{l}\text { Age } \\
<65 \\
\text { ye }\end{array}$ & $\begin{array}{l}(n) \\
>65 \\
\text { rs }\end{array}$ & $\begin{array}{l}\text { Presumed } \\
\text { NMDA } \\
\text { receptor } \\
\text { density }\end{array}$ & \multicolumn{2}{|c|}{$\begin{array}{c}\text { Cerebral } \\
\text { infarction } \\
\text { as cause } \\
\text { of death } \\
\mathrm{N} \%\end{array}$} \\
\hline Cerebral infarction & 77 & $48 / 29$ & 13 & 64 & $\uparrow$ & 21 & 27 \\
\hline $\begin{array}{l}\text { Dementia + cerebro- } \\
\text { vascular insufficiency }\end{array}$ & 522 & $313 / 209$ & 58 & 464 & $\uparrow=\downarrow$ & 52 & 10 \\
\hline Parkinson's disease & 34 & $21 / 13$ & 4 & 30 & $\downarrow$ & 3 & 11 \\
\hline $\begin{array}{l}\text { Other neurol. disorders } \\
\text { (Huntington's disease, } \\
\text { multiple sclerosis) }\end{array}$ & 45 & $18 / 27$ & 25 & 20 & $\uparrow$ & 9 & 20 \\
\hline Dementia of Alzheimer type & 64 & $6 / 58$ & 45 & 19 & $\downarrow$ & 3 & 5 \\
\hline Schizophrenia & 105 & $66 / 39$ & 45 & 60 & $\downarrow$ & 1 & 1 \\
\hline Depression & 40 & $29 / 11$ & 7 & 33 & ? & () & () \\
\hline
\end{tabular}

NMDA receptor densities are presumed to be increased $(\uparrow)$, decreased $(\downarrow)$ or unaltered $(=)$ in comparison with control subjects. Increased, decreased or unaltered pathway activity may occur in the same disease depending on the loop systems involved. The quantity of change, however, is dependent on the progress and duration of the disease. This information is not given here 


\section{The role of glutamate in schizophrenia}

It has recently been postulated that decreased glutamatergic function is a pathobiochemical marker of schizophrenia (Kim et al., 1980). A decreased release of glutamate has been found in the frontal and temporal cortex of schizophrenic patients (Sherman et al., 1991) while increased NMDA receptor density has been measured in the temporal and parietal cortex (Suga et al., 1990). In the putamen, increased (Kornhuber et al., 1989) and unaltered (Suga et al., 1990; Weissman et al., 1991) NMDA receptor densities have been reported. Quisqualate receptors are not changed in the frontal, temporal and parietal cortex (Kurumaji et al., 1990) while kainate receptor binding is increased in the frontal cortex (Deakin et al., 1989; Nishikawa et al., 1983) and not changed (Deakin et al., 1989) or decreased (Kerwin et al., 1988; Harrison et al., 1991) in the hippocampus. Taken together, the data available is of value only as a starting point for further research since both the number of studies and the number of brain regions examined are limited. For example, the most vulnerable brain regions in schizophrenia, the entorhinal cortex (Jakob and Beckmann, 1986) and the prefrontal cortex (Benes et al., 1986), have not been studied in detail and only preliminary biochemical evidence exists to suggest that NMDA receptor density is marginally increased in the entorhinal cortex (Kornhuber et al., 1989).

We assume that it is the loss of glutamatergic activity that induces an enhanced dopaminergic tone. The "dopamine hypothesis" of schizophrenia suggesting dopaminergic overactivity in the pathobiochemistry of some productive symptoms (paranoid hallucinatory psychosis) seems to be valid according to this assumption (Kornhuber et al., 1990).

\section{Anti-akinetic effects of glutamate antagonists and pharmacotoxic psychosis}

In Parkinson's disease enhanced glutamatergic activity is assumed to occur in the nucleus subthalamicus due to a decreased GABAergic input from the lateral globus pallidus. The cortico-striatal fibres also appear to be functionally over-active as the result of decreased dopaminergic nigrostriatal activity. By contrast, the glutamatergic thalamo-cortical pathway shows reduced activity due to GABAergic influence on the ventrolateral thalamus (Riederer and Berger, 1991).

The only anti-glutamatergic drugs available for the treatment of Parkinson's disease are the non-competitive NMDA receptor antagonists amantadine and memantine, which have only moderate anti-akinetic efficacy compared to dopamimetic substances (Schwab et al., 1969). However, threshold doses of memantine producing mild anti-akinetic effects result in pharmacotoxic psychosis in an unexpectedly high proportion of patients (Riederer et al., 1991). Amantadine is known to have antiparkinsonian effects and pharmacotoxic psychoses are frequent adverse reactions (Danielczyk, 1973). In Parkinson's disease there is a lack of data 


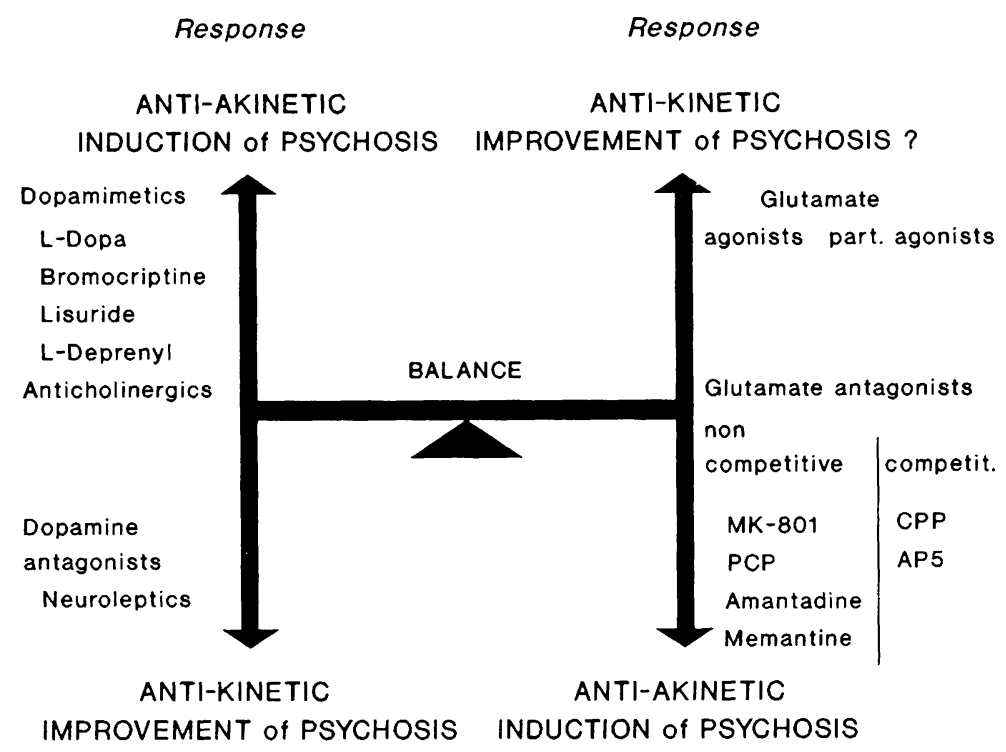

Fig. 1. Simplified illustration of glutamatergic-dopaminergic imbalances: anti-akinetic effects and psychosis

confirming a disturbance of glutamatergic function in limbic and cortical areas and supporting a glutamatergic hypothesis of pharmacotoxic psychosis. However, the fact that memantine has a considerable potential to induce pharmacotoxic psychosis at threshold doses which produce minor anti-akinetic effects, could suggest that glutamatergic activity in areas responsible for psychosis is reduced. Since under-active glutamatergic systems are further inhibited by NMDA receptor antagonists, adverse reactions such as pharmacotoxic psychosis are more likely to occur.

It is well known that all dopamimetic substances cause pharmacotoxic psychosis in Parkinson's disease and are able to aggravate productive symptoms in schizophrenia. It is not known, however, whether competitive NMDA receptor antagonists, which are known to enhance locomotor activity in experimental animals (Svensson et al., 1991; Löschmann et al., 1991), have potent anti-akinetic efficacy in Parkinson's disease or whether these substances also create the adverse reactions of dopamimetics and noncompetitive NMDA receptor antagonists. The development of competitive glutamatergic antagonists or of partial agonists/antagonists could be another strategy capable of producing anti-akinetic effects with only mild sideeffects. A simplified summary of this hypothesis is given in Fig. 1.

\section{References}

Benes FM, Davidson J, Bird ED (1986) Quantitative cytoarchitectural studies of the cerebral cortex of schizophrenics. Arch Gen Psychiatry 43: 31-35

Danielczyk W (1973) Die Behandlung von akinetischen Krisen. Med Welt 24: 1278 
Deakin JWF, Slater P, Simpson MDC, Gilchrist AC, Skan WJ, Royston MC, Reynolds GP, Cross AJ (1989) Frontal cortical and left temporal glutamatergic dysfunction in schizophrenia. J Neurochem 52: 1781-1786

Garthwaite G, Garthwaite J (1987) Receptor-linked ionic channels mediate N-methylD-aspartate neurotoxicity in rat cerebellar slices. Neurosci Lett 83: 241-246

Gibson GE, Peterson C (1987) Calcium and the aging nervous system. Neurobiol Aging 8: 329-343

Harrison PJ, McLaughlin D, Kerwin RW (1991) Decreased hippocampal expression of a glutamate receptor gene in schizophrenia. Lancet i: 450-452

Jakob H, Beckmann $H$ (1986) Prenatal developmental disturbances in the limbic allocortex in schizophrenics. J Neural Transm 65: 303-326

Kerwin RW, Patel S, Meldrum BS, Czudek C, Reynolds GP (1988) Asymmetrical loss of glutamate receptor subtype in left hippocampus in schizophrenia. Lancet $\mathrm{i}$ : $583-584$

Kim JS, Kornhuber HH, Schmid-Burgk W, Holzmüller B (1980) Low cerebrospinal fluid glutamate in schizophrenic patients and a new hypothesis on schizophrenia. Neurosci Lett 20: 379-382

Kornhuber J, Mack-Burkhardt F, Riederer P, Hebenstreit GF, Reynolds GP, Andrews $\mathrm{HB}$, Beckmann H (1989) $\left[{ }^{3} \mathrm{H}\right] \mathrm{MK}-801$ binding sites in postmortem brain regions of schizophrenic patients. J Neural Transm 77: 231-236

Kornhuber J, Riederer P, Beckmann H (1990) The dopaminergic and glutamatergic systems in schizophrenia. In: Bunney WE, Hippius H, Laakmann G, Schmau $\beta$ M (eds) Neuropsychopharmacology. Springer, Berlin Heidelberg New York Tokyo, pp 714-720

Kurumaji A, Ishimaru M, Toru M (1990) Quisqualate receptors in post-mortem brain of chronic schizophrenics. Proc Kyoto: New Trends in Schizophrenia and Mood Disorders Research, p 29

Löschmann PA, Lange KW, Kunow M, Rettig KJ, Jähnig P, Honore T, Turski L, Wachtel H, Jenner P, Marsden CD (1991) Synergism of the AMPA-antagonist NBQX and the NMDA-antagonist CPP with L-Dopa in models of Parkinson's disease. J Neural Transm [PD-Sect] 3: 203-213

Meldrum B, Garthwaite J (1990) Excitatory amino acid neurotoxicity and neurodegenerative disease. Trends Pharmacol Sci 11:379-387

Nishikawa T, Takashima M, Toru M (1983) Increased ${ }^{3} \mathrm{H}$-kainic acid binding in the prefrontal cortex in schizophrenia. Neurosci Lett 40: 245-250

Reynolds IR, Miller RJ (1988) Tricyclic antidepressants block N-methyl-D-aspartate receptors: similarities to the action of zinc. Br J Pharmacol 95: 95-102

Riederer P, Berger W (1991) Locomotion and behaviour: the interaction of loops and transmitter. Proc 5th World Congress of Psychiatry, Florence (in press)

Riederer P, Kornhuber J, Gerlach M, Danielczyk W, Youdim MBH (1991) Glutamatergic-dopaminergic imbalance in Parkinson's disease and paranoid hallucinatory psychosis. Proc Int Workshop on Parkinson's Disease, Berlin. Medicom Europe BV (in press)

Schwab RS, England AC, Poskanzer DC, Young RR (1969) Amantadine in the treatment of Parkinson's disease. J Am Med Assoc 208: 1168

Sherman AD, Davidson AT, Baruah S, Hegwood TS, Waziri R (1991) Evidence of glutamatergic deficiency in schizophrenia. Neurosci Lett 121: 77-80

Suga I, Kobayashi T, Ogata H, Toru M (1990) Increased ${ }^{3} \mathrm{H}-\mathrm{MK} 801$ binding sites in post-mortem brains of chronic schizophrenic patients. Proc Kyoto: New Trends in Schizophrenia and Mood Disorders Research, p 28

Svensson A, Pileblad E, Carlsson M (1991) A comparison between the non-competitive NMDA antagonist dizocilpine (MK-801) and the competitive NMDA antagonist D-CPPene with regard to dopamine turnover and locomotor-stimulatory properties in mice. J Neural Transm [Gen Sect] 85: 117-129 
Watkins JC, Kroogsgaard-Larsen P, Honore T (1990) Structure-activity relationships in the development of excitatory amino acid receptor agonists and competitive antagonists. Trends Pharmacol Sci 11: 25-33

Weissman AD, Casanova MF, Kleinman JE, London ED, DeSouza EB (1991) Selective loss of cerebral cortical sigma, but not PCP binding sites in schizophrenia. Biol Psychiatry 29: 41-54

Authors' address: Prof. Dr. P. Riederer, Clinical Neurochemistry, Department of Psychiatry, University of Würzburg, Füchsleinstrasse 15, D-W-8700 Würzburg, Federal Republic of Germany 